\title{
Structure Determination of MS-444; a New Myosin Light Chain Kinase Inhibitor
}

\author{
Yumiko Aotani and Yutaka SaItoH* \\ Tokyo Research Laboratories, Kyowa Hakko Kogyo Co., Ltd., \\ 3-6-6 Asahimachi, Machida, Tokyo 194, Japan
}

(Received for publication March 2, 1995)

\begin{abstract}
MS-444 is a novel myosin light chain kinase inhibitor, isolated from the culture broth of Micromonospora sp. KY7123. The structure of MS-444 was determined to be 5,8-dihydroxy-3methyl-(9H)-naphtho[2,3-c]furan-4-one by means of spectral analysis.
\end{abstract}

MS-444 (Fig. 1) ${ }^{1)}$, produced by Micromonospora sp. KY7123, is a compound which works as a inhibitor for myosin light chain kinase. In the previous paper $^{2)}$, fermentation, purification, and biological properties of MS-444 were reported. In this paper, we report its structure determination.

\section{Physico-chemical Properties}

The physico-chemical properties of MS-444 are summarized in Table 1. MS-444, obtained as yellow needles, didn't show clear melting point, and decomposed around $155^{\circ} \mathrm{C}$. The molecular weight $(230)$ and the molecular formula $\left(\mathrm{C}_{13} \mathrm{H}_{10} \mathrm{O}_{4}\right)$ of MS-444 were determined by EI-MS and HREI-MS respectively, and

Fig. 1. Structure of MS-444.

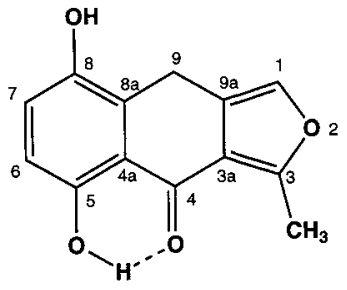

Table 1. Physico-chemical properties of MS-444

$\begin{array}{ll}\text { MPP }\left({ }^{\circ} \mathrm{C}\right) & 155(\mathrm{dec} \text {.) } \\ \text { HREI-MS } & \left.230.0596 \text { (Observed, } \mathrm{M}^{+}\right) \\ & \left.230.0579 \text { (Calculated for } \mathrm{C}_{13} \mathrm{H}_{10} \mathrm{O}_{4}\right) \\ \text { Molecular formula } & \mathrm{C}_{13} \mathrm{H}_{10} \mathrm{O}_{4} \\ \mathrm{UV} \lambda_{\max }{ }^{\text {MeOH }} \mathrm{nm}(\varepsilon) & \\ \text { (in neutral and acidic } & 203(17,000), 245(12,000) \\ \quad \text { solution ) } & 319(6,000), 387(3,800) \\ \text { (in basic solution ) } & 203(34,000), 228(14,000) \\ & 315(7,000), 431(2,500) \\ \mathrm{IR}_{\mathrm{KBr}} v_{\max } \mathrm{cm}^{-1} & 3388,1620,1604,1564,1473,1327, \\ & 1300,1273,1257\end{array}$

confirmed by ${ }^{1} \mathrm{H}$ and ${ }^{13} \mathrm{C}$ NMR spectra. The strong broad IR band at $3388 \mathrm{~cm}^{-1}$ indicated the presence of phenolic hydroxyl groups. Furthermore, a hypsochromic shift in base suggested the existanse of hydroquinone moiety. The absorptions at $1620 \mathrm{~cm}^{-1}(\mathrm{C}=\mathrm{O})$ and 1604 $\mathrm{cm}^{-1}(\mathrm{C}=\mathrm{C})$ suggested the presence of intramolecularyhydrogen-bonded carbonyl group. The optical rotation could not be measured because of the coloring.

\section{Structure Determination}

${ }^{13} \mathrm{C}$ NMR spectrum of MS-444 gave thirteen signals which is consistent with the molecular formula determined above. DEPT experiments showed the presence of one methyl (14.6 ppm), one methylene (20.4 ppm), and three $\mathrm{sp}^{2}$ methines (116.4 ppm, $124.6 \mathrm{ppm}, 138.0 \mathrm{ppm}$ ). The other eight quaternary carbon signals were assigned to be one carbonyl carbon ( $189.7 \mathrm{ppm})$, three oxygenbearing aromatic carbons $(147.8 \mathrm{ppm}, 158.6 \mathrm{ppm}, 159.2$ $\mathrm{ppm}$ ), and four aromatic carbons (117.5 ppm, $118.2 \mathrm{ppm}$, $122.9 \mathrm{ppm}, 128.0 \mathrm{ppm})$. In ${ }^{1} \mathrm{H}$ NMR spectrum, except carbon-bonded protons, two hydroxy-protons were observed and one of which was hydrogen-bonded $(12.6 \mathrm{ppm})$. These data agree well with the above properties.

Two aromatic protons $(6.69 \mathrm{ppm}, 7.13 \mathrm{ppm})$ were assumed to be in ortho position from the $8.8 \mathrm{~Hz}$ coupling. In proton-nondecoupling ${ }^{13} \mathrm{C}$ NMR, a $206 \mathrm{~Hz} \mathrm{C}-\mathrm{H}$ coupling was observed for ${ }^{13} \mathrm{C}$ that resonates at 138.0 $\mathrm{ppm}$, which indicates the presense of furan ring moiety.

The $\mathrm{C}-\mathrm{H}$ bonding were assigned by the analysis of proton selective decoupling ${ }^{13} \mathrm{C}$ NMR spectra. The whole structure was established by COLOC (Correlation of Long Range Coupling) experiment shown in Fig. 2. The ${ }^{1} \mathrm{H}$ and ${ }^{13} \mathrm{C}$ NMR signal assignments are summarized in Table 2.

After the construction of the structure, one coupling 
Fig. 2. ${ }^{1} \mathrm{H}_{-}{ }^{13} \mathrm{C}$ long-range couplings (COLOC experimemts) of MS-444.

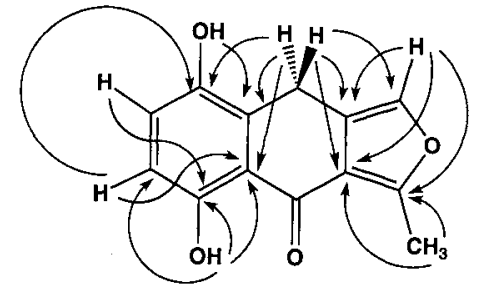

Arrows are directing from $\mathrm{H}$ to $\mathrm{C}$.

Table 2. ${ }^{13} \mathrm{C}$ and ${ }^{1} \mathrm{H}$ NMR chemical shifts $(\delta$, ppm) of MS-444 in acetone- $d_{6}$.

\begin{tabular}{|c|c|c|c|c|}
\hline Position & ${ }^{13} \mathrm{C}$ & & & ${ }^{1} \mathrm{H}$ \\
\hline 1 & 138.0 & d & 7.53 & $(1 \mathrm{H}, \mathrm{t}, \mathrm{J}=1.7 \mathrm{~Hz})$ \\
\hline 3 & 159.2 & s & & \\
\hline $3 a$ & 117.5 & $\mathrm{~s}$ & & \\
\hline 4 & 189.7 & $\mathrm{~s}$ & & \\
\hline $4 a$ & 118.2 & $s$ & & \\
\hline 5 & 158.6 & s & & \\
\hline 6 & 116.4 & d & 6.69 & $(1 \mathrm{H}, \mathrm{dt}, \mathrm{J}=8.8,0.9 \mathrm{~Hz})$ \\
\hline 7 & 124.6 & $\mathrm{~d}$ & 7.13 & $(1 \mathrm{H}, \mathrm{d}, \mathrm{J}=8.8 \mathrm{~Hz})$ \\
\hline 8 & 147.8 & $\mathrm{~s}$ & & \\
\hline $8 a$ & 128.0 & $s$ & & \\
\hline 9 & 20.4 & $\mathrm{t}$ & 3.93 & $(2 \mathrm{H}, \mathrm{dd}, \mathrm{J}=1.7,0.9 \mathrm{~Hz}$ \\
\hline $9 \mathrm{a}$ & 122.9 & $\mathrm{~s}$ & & \\
\hline 3- $\mathrm{CH}_{3}$ & 14.6 & $q$ & 2.68 & $(3 \mathrm{H}, \mathrm{s})$ \\
\hline $5-\mathrm{OH}$ & & & 12.60 & $(1 \mathrm{H}, \mathrm{s})$ \\
\hline 8-OH & & & 8.28 & $(1 \mathrm{H}, \mathrm{s})$ \\
\hline
\end{tabular}

observed in proton homodecoupling experiment was found to be a strange result; the $0.9 \mathrm{~Hz}$ coupling observed between 6-H and 9-Hs is unusual for such protons that have 6 bonds between them. We assume that 9-Hs are somehow stereo-positioned in the optimal way for this long-range ${ }^{1} \mathrm{H}-{ }^{1} \mathrm{H}$ coupling.

\section{Discussion}

MS-444 possesses a unique $4(9 H)$-naphtho[2,3c]furanone structure. This structure was found in two synthesis reports ${ }^{3,4)}$ as intermediates of aromatic ortho diketones. And while we were preparing this manuscript 5-hydroxy-3-methy-derivative was isolated from Cape aloe ${ }^{5)}$. But there are no previous reports for any biological activities. As MS-444 has a potent bioactivity ${ }^{2)}$, the structure will be able to act as a lead for new drugs.

\section{Experimental}

Melting point was determined with a Yanagimoto melting point apparatus. EI-MS spectrum was measured with a HITACHI M-80B mass spectrometer. IR spectrum was taken on a JEOL JIR-RFX3001 spectrometer. NMR spectra were recorded on a Bruker AM400 spectrometer using TMS as an internal standard.

\section{References}

1) Nakanishi, S.; S. Chiba, I. Kawamoto, Y. Aotani, Y. SaITOH, K. Yamada \& Y. Matuda: Compound MS-444 manufacture with Micromonospora. PCT Int. Appl. WO 9309109 A1 930513

2) Nakanishi, S.; S. Chiba, H. Yano, I. Kawamoto \& Y. MATUDA: MS-444, a new inhibitor of myosin light chain kinase from Micromonospora sp. KY7123. J. Antibioticsics 48: $948 \sim 951,1995$

3) Lepage, Y. \& D. Villessot: Déshydratation de diols naphto-(2.3c) furanniques bisecondaires. C. R. Acad. Sci., Ser. C 274: $1410 \sim 1412,1972$

4) Villessot, D. \& Y. LePage: Reactivity of Naphtho[2,3c] furandiols. Application to the Synthesis of Aromatic ortho-Diketones. J. Chem. Research., Synop.: 300 301, 1979

5) Koyama, J.; T. Ogura \& K. Tagahara: Naphtho[2,3c]furan-4,9-dione and its derivatives from Aloe ferox. Phytochemistry 37: 1147 1148, 1994 